\title{
Vegetative and productive aspects of organically grown coffee cultivars under shaded and unshaded systems
}

\author{
Marta dos Santos Freire Ricci ${ }^{1 *}$, Janaina Ribeiro Costa Rouws ${ }^{1}$, Nelson Geraldo de Oliveira ${ }^{2}$, \\ Marinete Bezerra Rodrigues ${ }^{3}$ \\ ${ }^{1}$ Embrapa Agrobiologia, C.P. 74505 - 23851-970 - Seropédica, RJ - Brasil. \\ ${ }^{2}$ UNESP/FCA, C.P. 237 - 18610-307 - Botucatu, SP - Brasil. \\ ${ }^{3}$ UFRRJ - Programa de Pós-Graduação em Agricultura Orgânica - 23851-970 - Seropédica, RJ - Brasil. \\ *Corresponding author <marta@cnpab.embrapa.br> \\ Edited by: Edmilson José Ambrosano
}

\begin{abstract}
Although Coffea arabica species has its origin in the African understories, there is great resistance on the part of the Brazilian producers for growing this species under agroforestry systems as they fear that shading reduces production. This study aimed at evaluating some vegetative traits and the productivity of organically grown coffee (Coffea arabica L.) cultivars under shaded and unshaded systems. Twelve treatments consisting of two cultivation systems (shaded and unshaded) and six coffee cultivars were arranged in randomized blocks with four replicates, in a split-plot scheme. Shading was provided by banana (Musa sp.) and coral bean plants (Erythrina verna). Shading delayed fruit maturation. Late maturation cultivars, such as the Icatu and the Obatã, matured early in both cultivation systems, while medium and early maturation cultivars presented late maturation. Cultivation in the shaded system increased the leaf area and the number of lower branches, decreased the number of productive nodes per branch, and increased the distance between the nodes and the number of leaves present in the branches. Cultivation in the unshaded system presented greater number of plants with branch blight in relation to plants grown in the shade. The productivity of the cultivars was not different, at 30.0 processed bags per hectare in the shaded system, and 25.8 processed bags per hectare in the unshaded system. The most productive cultivars in the shaded system were the Tupi, the Obatã, and the Catuaí, while no differences between cultivars were obtained in the unshaded system.

Key words: Coffea arabica L., organic coffee, agroforestry system, productivity
\end{abstract}

\section{Introduction}

From an environmental point of view, Brazilian organic coffee (Coffea arabica L.) production has as its weakness the fact that most crops are unshaded monocrops (Ricci et al., 2002), despite the fact that low diversity makes agricultural systems biologically unstable (Gliessman, 2000; Altieri et al., 2003). Although the Coffea arabica specie has its origin in the African understories (Guerreiro Filho et al., 2008), there is great resistance in Brazil on the part of the producers for growing this species under agroforestry systems.

Among the most important positive aspects of the association of coffee plants with trees, as reviewed by Matsumoto (2004), the following stands out: (i) increase in cultivation longevity; (ii) improvement of soil conditions (increase of the content of organic matter, (iii) higher nutrient cycling, (iv) reduction of soil compaction, (v) increase of water infiltration, (vi) reduction of erosion; (vii) improvement of climatic conditions for coffee plants; (viii) lower demand for nutrients; (ix) reduced need for hoeings; (x) reduction in the occurrence of pests and diseases; (xi) protection against winds and frosts; (xii) slower and more uniform maturation of fruits. As a disadvantage, it can be mentioned the reduction of the production due to competition from trees for light, water and nutrients.

The lack of information and technological support required to make organic coffee cropping systems more adequate has prevented growers from obtaining higher yields.
In this sense, the lack of cultivars developed for organic systems is a limitation for achieving higher productivity, since the same cultivars developed for conventional production are utilized. These cultivars were developed by traditional breeding programs, based on the usage of large amounts of fertilizers and pesticides (Moura et al., 2005b).

This study aimed at evaluating some vegetative traits and yield of six coffee cultivars when grown in the organic system, both in shaded and unshaded conditions.

\section{Materials and Methods}

The work was conducted in Juparanã, District of Valença, Rio de Janeiro State, Brazil, 22 $20^{\circ}$ S and $43^{\circ} 43^{\prime}$ W, on an area with less than $10 \%$ slope and altitude of $608 \mathrm{~m}$. The annual average precipitation and temperature over the past ten years were $1163 \mathrm{~mm}$ and $25.5^{\circ} \mathrm{C}$, respectively. The experiment consisted of 12 treatments distributed in random blocks, with four replicates, in a split-plot arrangement. Two cultivation systems were evaluated in the plots: coffee grown in an unshaded system (monocrop), and coffee shaded by banana plants (Musa sp.), var. Prata Comum, and by coral bean plants (Erythrina verna).

The following six cultivars were evaluated in subplots: Tupi IAC 1669-33, which features short stature plants, early maturation, good productivity, and high resistance to rust; Oeiras MG 6851, short stature plants, medium to late maturation, high productivity and moderate resistance to rust; Icatu amarelo IAC 3282, tall plants, early maturation, high 
productivity, and moderate resistance to rust; Catucaí amarelo 2SL, short to medium-sized plants, medium maturation, high productivity and moderate resistance to rust; Obatã vermelho IAC 1669-20, short stature plants, very late maturation, high productivity, and high resistance to rust; Catuaí vermelho IAC 144, short stature plants, late maturation, high productivity, and susceptible to rust (Carvalho et al., 2008).

Each subplot consisted of four coffee plant rows established at a spacing of $2.5 \mathrm{~m} \times 0.7 \mathrm{~m}$ in February 2001. The coral beans and banana plants were planted at spacing of $9 \mathrm{~m}$ $\times 5 \mathrm{~m}$ and $3 \mathrm{~m} \times 5 \mathrm{~m}$, respectively, and were arranged in the two most external inter-rows of the plots. The banana plants remained in the area until November 2007, when the coral bean plants reached an approximate height of seven meters.

In 2001 the soil had the following chemical characteristics: $\mathrm{pH}, 5.3$ (in water); $\mathrm{Al}, 1 \mathrm{mmol} \mathrm{dm} \mathrm{dm}^{-3}$; Ca, $18 \mathrm{mmol}$ $\mathrm{dm}^{-3} ; \mathrm{Mg}, 7 \mathrm{mmol} \mathrm{dm}^{-3} ; \mathrm{P}, 2.0 \mathrm{mg} \mathrm{dm}^{-3} ; \mathrm{K}, 128 \mathrm{mg} \mathrm{dm}^{-3}$; organic carbon, $1.35 \%$; base saturation (V\%), $56.5 \%$ (Embrapa, 1997). Supplementary fertilizations were applied between the months of November and February and, because this was a long term experiment, fertilization varied from year to year according to soil and leaf analysis results. Poultry litter manure (average content of: $1.7 \%$ of N) was applied as a source of nitrogen in doses ranging from 0.25 to $2.5 \mathrm{~kg}$ per plant, complemented with applications of 200 to $500 \mathrm{~g}$ per plant castor bean cake ( 5 to $6 \% \mathrm{~N})$. In the first year, $100 \mathrm{~g}$ of magnesium thermophosphate per plant was applied as a source of phosphorus $\left(16.5 \% \mathrm{P}_{2} \mathrm{O}_{5}\right.$ soluble in citric acid) and, in the other years, bone powder doses were applied $\left(20 \% \mathrm{P}_{2} \mathrm{O}_{5}\right.$ soluble in citric acid; $\left.1.5 \% \mathrm{~N} ; 22 \% \mathrm{Ca}\right)$, varying between 300 and $500 \mathrm{~g}$ per plant. When needed, potassium was supplied by the application of potassium, and magnesium sulfate $\left(22 \% \mathrm{~K}_{2} \mathrm{O}\right.$ and $\left.11 \% \mathrm{MgO}\right)$, in dosages ranging from 100 to $150 \mathrm{~g}$ per plant.

The experimental area included $33 \%$ of shading, according to the methodology proposed by Haggar et al. (2001). No management was conducted in eritrina pruning, as it was still in its growing process, while the banana trees were treated three to four times a year to avoid excessive tillering when the dry leaves were also being removed.

In April 2006, based on six randomly selected plants in each subplot, the cultivars were evaluated according to the following parameters: height $(\mathrm{m})$ and stem diameter $(\mathrm{cm})$; crown diameter $(\mathrm{m})$; leaf area $\left(\mathrm{cm}^{2}\right)$; number of side branches or plagiotropic branches from the ground up to half of the plant (lower half) and from the middle to the end (upper half). Samples of 30 leaves taken from the third pair of leaves, branches from the edge of the upper third of the plant were employed to determine the leaf area using a LICOR 3100 measuring device (Ricci et al., 2006).

Based on three randomly selected branches from the upper, middle and bottom of the coffee plant, evaluations were made of the number of productive nodes and leaves per branch, the distance between the nodes (the fourth rosette from the branch tip) and the percentage of green, ripe and dry fruit present in the branches of the different thirds of the plant. In August 2006, after harvesting, the occurrence of gaps or dead plants in the subplots, as well as the number of plants with 'branches blight' was evaluated.

During the period 2004 to 2009 , cultivar productivity was evaluated based on ten randomly selected plants and expressed in 60-kg bags processed per hectare. The 2008 harvest did not crop up since the coffee plants were pruned of the orthotropic branches in 2007.

Analysis of variance was performed using the SISVAR software program, and the mean comparison was made by the Scott-Knott $(p<0.05)$, except for the variable number of plants with 'branch blight' per subplot, which was considered to be $10 \%$. The original data for percentage of dry fruits in the upper, middle, and lower thirds of the plants were transformed into $\log (X+1)$, and the variable distance between the nodes in the middle and lower thirds was transformed into $\log (\mathrm{X})$.

\section{Results and Discussion}

Shading delayed fruit maturation (Figure 1). At the beginning of harvest (April 2006), a higher percentage of green fruits was observed in the upper, middle, and lower thirds in the shaded system, with $65.3 \%, 73.0 \%$, and $91.4 \%$, respectively, while for plants which are grown in the unshaded system values of $33.6 \%, 40.3 \%$, and $65.7 \%$ were obtained, respectively (cultivar mean). On the other hand, the percentages of mature fruits in the upper, middle, and lower thirds were higher for plants grown in the unshaded system at $49.7 \%, 42.0 \%$, and $26.7 \%$, respectively, against $33.3 \%, 25.1 \%$, and $7.8 \%$ in the shaded system. The same trend was observed in relation to the presence of dry fruits, with $16.7 \%$, $17.7 \%$, and $7.6 \%$ in the shaded system, respectively, against $1.4 \%, 1.9 \%$, and $0.8 \%$, respectively, in the crop grown in the unshaded system.

The Icatu and the Obatã cultivars were the earliest, as evidenced by the lower percentages of green fruits present in the upper third of the coffee plant in both cultivation systems (Figure 1), and by the higher percentages of mature and dry fruits, though according to Moura et al. (2005b) and Carvalho et al. (2008) they are considered medium or late maturation cultivars. On the other hand, the Oeiras and the Tupi cultivars, which are considered early (Carvalho et al., 2008), showed high percentages of green fruits and low percentages of mature and dry fruits on the plants in both systems, and did not differ from cultivars that are considered late, such as Catuaí (Figure 1). The Catucaí cultivar had late maturation in the shaded system. For coffee grown in the unshaded system, this cultivar showed the smallest percentages of green fruits and the greatest percentages of dry fruits in the upper third, though it is considered to be a medium maturation cultivar (Carvalho et al., 2008).

Shading did not affect the average height of cultivars (Table 1); this result was also observed by Lemos et al. (2007), who studied unshaded coffee and coffee plants shaded with avocado and ice-cream-bean (Inga edulis) trees. When grown in the shade, the Icatu cultivar showed the greatest height, followed by the other cultivars, which were not different from one another, although this result was expected, since the Icatu is the only cultivar considered to be 
tall (Carvalho et al., 2008). For the unshaded coffee there was a greater distinction between cultivars, with the Icatu having the greatest height, followed by the Catuaí, while the other cultivars had the lowest averages.

Stem diameter was not affected by cultivation systems; in addition, the various cultivars were not different from one another (Table 1). Similarly, the crown diameter was not affected by the cultivation system as it was already observed by Lemos et al. (2007). In the shaded system, the Icatu cultivar had the greatest crown diameter, while in the unshaded system, the Icatu and the Catuai cultivars showed the greatest diameters, followed by the Tupi and the Oeiras cultivars, which were not different from one another, and by the Obatã cultivar, which had the smallest diameter.

The number of lower branches was smaller for unshaded coffee (mean of all cultivars), which explains the visually perceived difference in the field, where coffee plants grown in the sun visually had the bottom part of their canopies higher than shaded plants. In both systems, the cultivars were not different from each other (Table 1). There were no differences between systems in relation to the number of upper branches. In the shaded system, all cultivars had the same number of upper branches. However, in the unshaded system, the Catuaí cultivar had the highest number of branches in relation to the other cultivars.
The average leaf area of the cultivars was higher in the shaded system, with the highest values observed in the Tupi, the Obatã, and the Catuaí vermelho cultivars (Table 1), while in the unshaded system the Tupi, the Obatã, and the Oeiras cultivars had the highest values. Increased leaf area was reported by other authors (Cannell, 1985; Fahl et al., 1994; Larramendi and Aballes, 1995; Lemos et al., 2007). Ricci et al. (2006) who observed that shading provided higher leaf area values, but did not change the leaf dry matter. Morais et al. (2003) reported that coffee plants shaded by pigeon pea grown in the cultivation inter-rows increased the individual size of coffee leaves, while plants grown in the unshaded system developed smaller and denser leaves, with thicker cell walls, cuticles, and mesophylls. These alterations characterize the development of mechanical reinforcements in the plant in order to prevent water loss (Morais et al., 2003). Coffee plants increased their leaf area as a strategy to increase light capture (Righi et al., 2008). Increased leaf area is one of the factors that contribute towards increase in production (Cannell, 1985).

A reduction in the number of productive nodes per branch and an increase in the distance between them were observed in the upper and middle thirds of the coffee plants grown under shade (Table 2). The smallest number of nodes was obtained for shaded Oeiras and Obatã cultivars, while
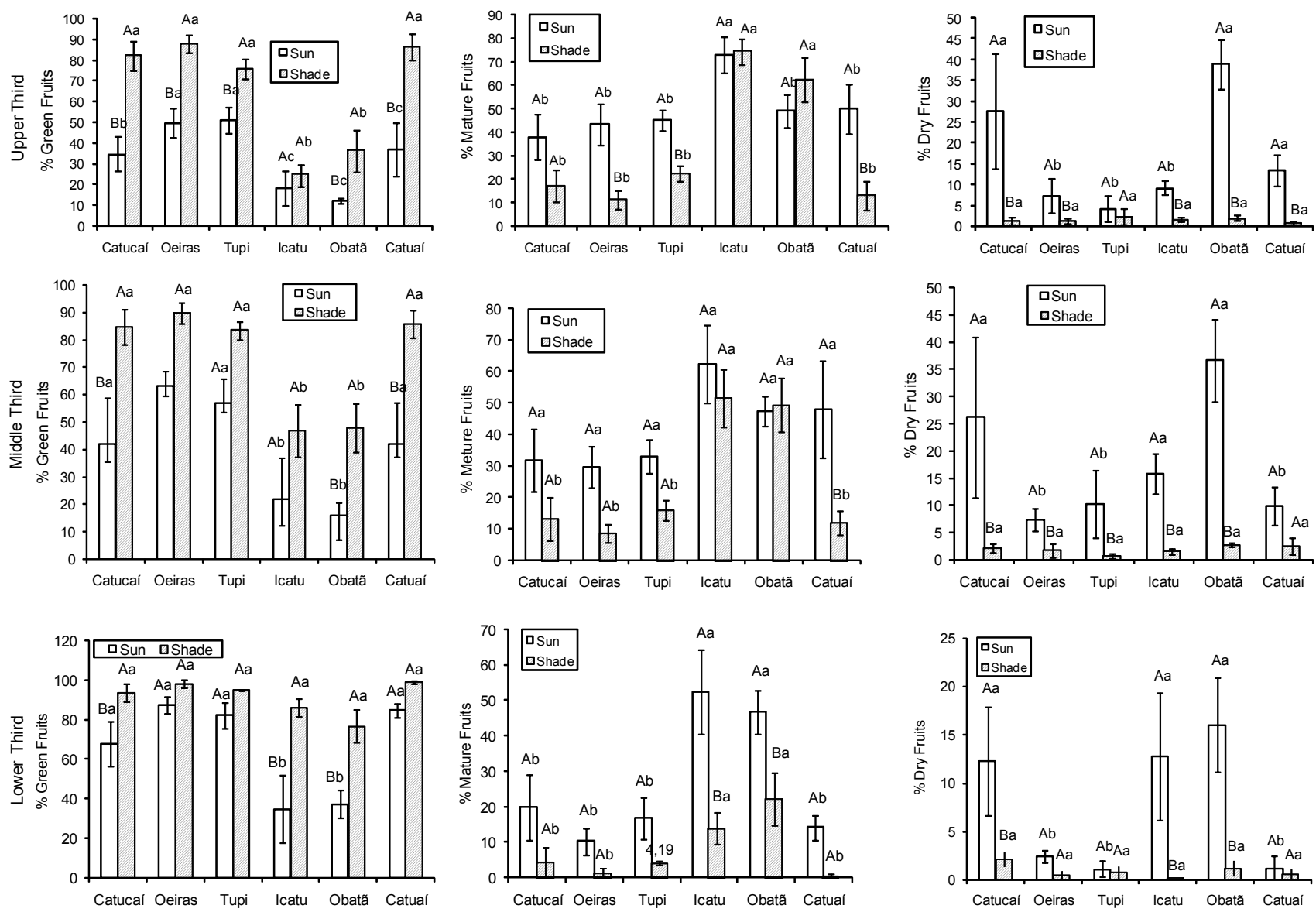

Figure 1 - Mean percentages of fruits harvested at the green, mature, and dry stages, present in the upper, middle, and lower thirds of coffee cultivars in unshaded and shaded systems. April 2006. 
Table 1 - Mean values for height, stem and crown diameters, leaf area, number of branches in the upper and lower parts of the cultivars, number of dead plants, and number of plants with 'branch blight' in subplots of unshaded and shaded systems. April 2006.

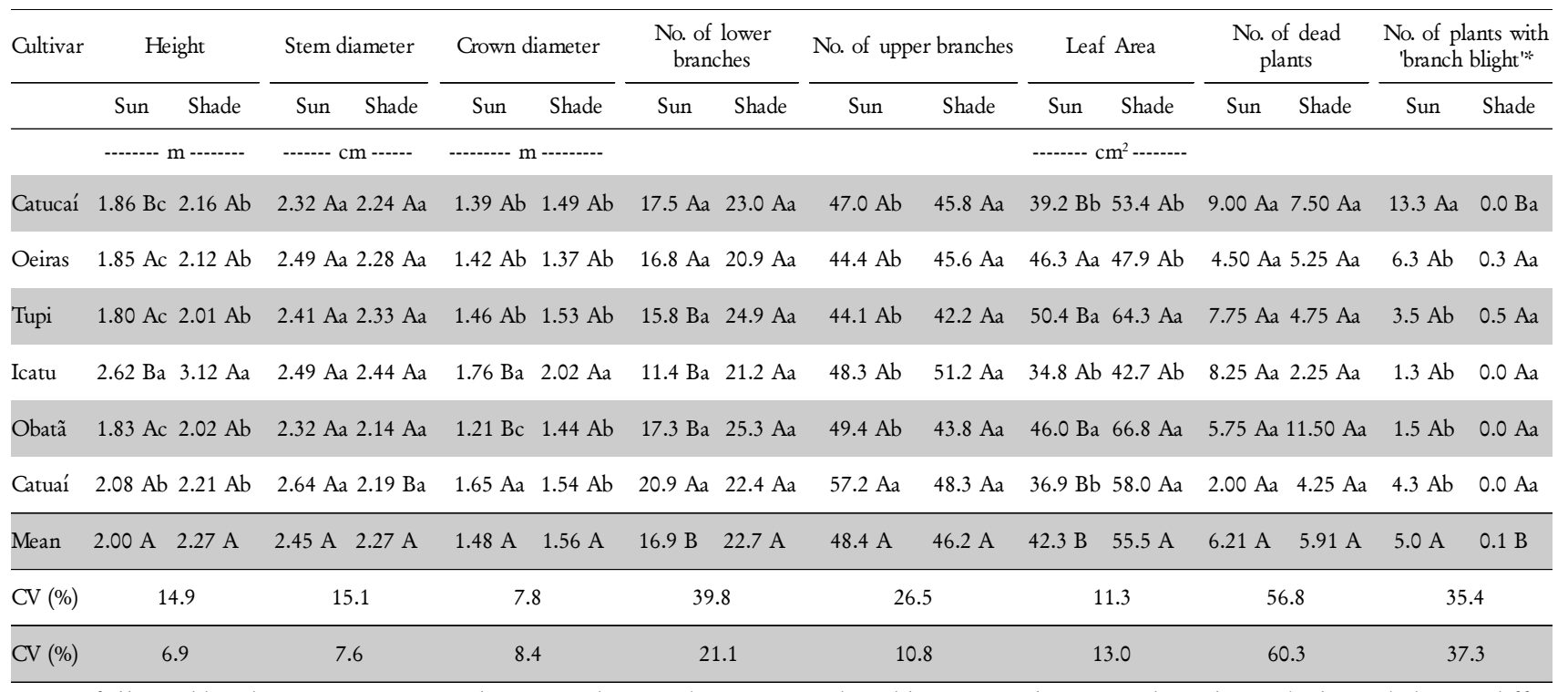

Means followed by the same upper case letters in the row (management) and lower case letters in the column (cultivars) do not differ (Scott-Knott test, $p<0.05)$. *Scott-Knott test $(p<0.10) . \mathrm{V}_{1}=$ coefficient of variation for systems; $\mathrm{CV}_{2}=$ coefficient of variation for cultivars.

for unshaded coffee the smallest numbers of nodes were obtained for Oeiras, Tupi, and Obatã.

The variable distance between nodes was strongly influenced by shading, whereas there was no difference among cultivars in either thirds of the plant in the unshaded system. However, in shaded system, Icatu and Tupi cultivars showed the highest distances between nodes in the upper and middle thirds of the coffee plants, respectively (Table 2).

In the shaded system a higher number of leaves was observed present in the branches of the middle and upper thirds (cultivars average), and the Tupi and Icatu cultivars had the highest leaf number (Table 2). The Icatu cultivar also remained with the larger number of leaves in the unshaded system. In the middle third, the Tupi cultivar had the highest number of leaves in relation to the other cultivars when grown in the shaded system. However, there were no differences between these cultivars when grown in the unshaded system.

In 2006, after the fourth harvest, the numbers of gaps or dead plants in the subplots were identical in both shaded and unshaded systems (of all cultivars average), without differences between cultivars (Table 1). At that time the appearance of coffee plants with apical bud death of branches was also observed; this is also known as 'branch blight' or 'die-back' (Ricci et al., 2007). The number of plants showing this disorder was higher in coffee grown in the unshaded system: 5.0 plants per subplot on average (Table 1), against 0.1 plants per subplot in the shaded system. In coffee grown in the unshaded system, the Catucaí cultivar showed the highest number of plants with 'branch blight'; in shaded coffee plants, however, there were no differences between cultivars.
'Branch blight' is a disorder associated with different causes, such as: high production leading to depletion of nutritional reserves and starch; high temperatures and water deficit (Carvalho et al., 1993; 2008); nitrogen (Montoya and Umaña, 1961) and potassium deficiency (Magalhães, 2006). The lower occurrence of branch blight observed in the shaded system in relation to coffee grown in the unshaded system might be related to the protection offered by trees and banana plants, providing lower temperatures, greater nutrient cycling, and higher inflow of nitrogen into the system, since the coral bean is a legume that has the ability to fix nitrogen. Although soil moisture was not evaluated, the higher presence of leaves in coffee plant branches grown in the shaded system (Table 2) suggests a better water supply condition of this system, which may have contributed towards a lower occurrence of branch blight.

Although shading reduced the number of nodes per branch, which is considered by Cannell (1985) as a very important variable for individual coffee plant productivity, the average productivity of cultivars was not influenced by the shaded and the unshaded cultivation systems, as up to 30.0 bags per hectare were processed in the shaded system (average of five years), while 25.8 bags per hectare were processed in the unshaded system (average of four years) (Table 3).

It is possible that other factors not assessed in this study have helped to offset the reduction in the number of nodes per branch, such as lower leaf and environmental temperature (Freitas et al., 2003), better water supply conditions (Da Matta, 2004). Jaramillo-Botero et al. (2006) evaluated the effect of light and nutrients availability on the reproductive development and production of coffee plants submitted to different levels of radiation. They concluded that plants under $48 \%$ shading, fertilized with $40 \%$ of the recommended 
Table 2 - Mean numbers of productive nodes, number of leaves, and distance between nodes in branches located in the upper, middle, and lower thirds of coffee cultivars, in subplots of unshaded and shaded systems. April 2006.

\begin{tabular}{|c|c|c|c|c|c|c|c|}
\hline \multirow{2}{*}{ Plant third } & \multirow{2}{*}{ Cultivar } & \multicolumn{2}{|c|}{ No. of nodes per branch } & \multicolumn{2}{|c|}{ Distance between nodes $(\mathrm{cm})$} & \multicolumn{2}{|c|}{ No. of leaves per branch } \\
\hline & & Sun & Shade & Sun & Shade & Sun & Shade \\
\hline \multirow{6}{*}{ Upper } & Catucaí & $16.9 \mathrm{Aa}$ & $14.3 \mathrm{Ba}$ & $2.19 \mathrm{Ba}$ & $3.00 \mathrm{Ab}$ & $7.0 \mathrm{Bb}$ & $14.7 \mathrm{Ab}$ \\
\hline & Oeiras & $15.8 \mathrm{Ab}$ & $12.7 \mathrm{Bb}$ & $2.44 \mathrm{Ba}$ & $3.09 \mathrm{Ab}$ & $7.0 \mathrm{Bb}$ & $12.5 \mathrm{Ab}$ \\
\hline & Tupi & $17.0 \mathrm{Aa}$ & $13.2 \mathrm{Bb}$ & $2.26 \mathrm{Ba}$ & $3.67 \mathrm{Aa}$ & $9.1 \mathrm{Bb}$ & 17.1 Aa \\
\hline & Icatu & $18.5 \mathrm{Aa}$ & $15.0 \mathrm{Ba}$ & $2.64 \mathrm{Ba}$ & $3.90 \mathrm{Aa}$ & $14.3 \mathrm{Ba}$ & $20.5 \mathrm{Aa}$ \\
\hline & Obatã & $14.5 \mathrm{Ab}$ & $13.2 \mathrm{Ab}$ & $2.20 \mathrm{Ba}$ & $3.40 \mathrm{Ab}$ & $3.6 \mathrm{Bb}$ & $14.2 \mathrm{Ab}$ \\
\hline & Catuaí & $17.4 \mathrm{Aa}$ & 14.4 Ba & $2.21 \mathrm{Ba}$ & $3.13 \mathrm{Ab}$ & $5.4 \mathrm{Bb}$ & $12.8 \mathrm{Ab}$ \\
\hline Mean & & $16.7 \mathrm{~A}$ & $13.8 \mathrm{~B}$ & $2.33 \mathrm{~B}$ & $3.36 \mathrm{~A}$ & $7.7 \mathrm{~B}$ & $15.3 \mathrm{~A}$ \\
\hline CV1 (\%) & & \multicolumn{2}{|c|}{9.5} & \multicolumn{2}{|c|}{14.0} & \multicolumn{2}{|c|}{40.7} \\
\hline CV2 (\%) & & \multicolumn{2}{|c|}{7.6} & \multicolumn{2}{|c|}{10.5} & \multicolumn{2}{|c|}{29.1} \\
\hline \multirow{6}{*}{ Middle } & Catucaí & $27.7 \mathrm{Ab}$ & $22.8 \mathrm{Ba}$ & $1.76 \mathrm{Bc}$ & $2.62 \mathrm{Ab}$ & $3.5 \mathrm{Ba}$ & $7.8 \mathrm{Ab}$ \\
\hline & Oeiras & $25.3 \mathrm{Ac}$ & $21.5 \mathrm{Aa}$ & $2.14 \mathrm{Bb}$ & $2.14 \mathrm{Ab}$ & $4.0 \mathrm{Aa}$ & $7.7 \mathrm{Ab}$ \\
\hline & Tupi & $28.4 \mathrm{Ab}$ & $21.1 \mathrm{Ba}$ & $1.95 \mathrm{Bc}$ & $1.95 \mathrm{Aa}$ & $4.4 \mathrm{Ba}$ & 14.2 Aa \\
\hline & Icatu & $29.0 \mathrm{Ab}$ & $23.4 \mathrm{Ba}$ & $2.60 \mathrm{Ba}$ & $2.60 \mathrm{Aa}$ & $5.7 \mathrm{Ba}$ & $10.3 \mathrm{Ab}$ \\
\hline & Obatã & $24.0 \mathrm{Ac}$ & $19.7 \mathrm{Ba}$ & $2.13 \mathrm{Bb}$ & $2.13 \mathrm{Ab}$ & $0.9 \mathrm{Ba}$ & $9.6 \mathrm{Ab}$ \\
\hline & Catuaí & $33.3 \mathrm{Aa}$ & $25.0 \mathrm{Ba}$ & $1.70 \mathrm{Bc}$ & $1.70 \mathrm{Ab}$ & $3.0 \mathrm{Aa}$ & $6.3 \mathrm{Ab}$ \\
\hline Mean & & $28.0 \mathrm{~A}$ & $22.2 \mathrm{~B}$ & $2.05 \mathrm{~B}$ & $2.82 \mathrm{~A}$ & $3.6 \mathrm{~B}$ & $9.5 \mathrm{~A}$ \\
\hline CV $1(\%)$ & & \multicolumn{2}{|c|}{17.1} & \multicolumn{2}{|c|}{4.0} & \multicolumn{2}{|c|}{50.8} \\
\hline CV 2 (\%) & & \multicolumn{2}{|c|}{9.7} & \multicolumn{2}{|c|}{11.7} & \multicolumn{2}{|c|}{41.2} \\
\hline \multirow{6}{*}{ Lower } & Catucaí & $28.4 \mathrm{Ab}$ & $26.2 \mathrm{Aa}$ & $1.87 \mathrm{Bb}$ & $2.55 \mathrm{Ab}$ & $3.0 \mathrm{Ab}$ & $6.0 \mathrm{Aa}$ \\
\hline & Oeiras & $23.4 \mathrm{Ac}$ & $22.9 \mathrm{Ab}$ & $2.36 \mathrm{Ba}$ & $3.62 \mathrm{Aa}$ & $2.2 \mathrm{Bb}$ & $5.5 \mathrm{Aa}$ \\
\hline & Tupi & $26.3 \mathrm{Ab}$ & $24.9 \mathrm{Aa}$ & $2.22 \mathrm{Ba}$ & $3.15 \mathrm{Aa}$ & $4.5 \mathrm{Aa}$ & $6.3 \mathrm{Aa}$ \\
\hline & Icatu & $18.0 \mathrm{Ac}$ & $20.0 \mathrm{Ab}$ & $2.33 \mathrm{Aa}$ & $3.06 \mathrm{Aa}$ & $5.0 \mathrm{Aa}$ & $5.4 \mathrm{Aa}$ \\
\hline & Obatã & $19.1 \mathrm{Ac}$ & $22.1 \mathrm{Ab}$ & $2.60 \mathrm{Aa}$ & $2.96 \mathrm{Aa}$ & $1.3 \mathrm{Bb}$ & $6.1 \mathrm{Aa}$ \\
\hline & Catuaí & $36.7 \mathrm{Aa}$ & $30.4 \mathrm{Ba}$ & $1.78 \mathrm{Ab}$ & $2.30 \mathrm{Ab}$ & $3.0 \mathrm{Ab}$ & $5.0 \mathrm{Aa}$ \\
\hline Mean & & $25.3 \mathrm{~A}$ & $24.4 \mathrm{~A}$ & $2.19 \mathrm{~A}$ & $2.94 \mathrm{~A}$ & $3.2 \mathrm{~A}$ & $5.7 \mathrm{~A}$ \\
\hline $\mathrm{CV}_{1}(\%)$ & & \multicolumn{2}{|c|}{9.0} & \multicolumn{2}{|c|}{35.0} & \multicolumn{2}{|c|}{70.3} \\
\hline $\mathrm{CV}_{2}(\%)$ & & \multicolumn{2}{|c|}{15.4} & \multicolumn{2}{|c|}{20.5} & \multicolumn{2}{|c|}{38.7} \\
\hline
\end{tabular}

Means followed by the same upper case letters in the row (management) and lower case letters in the column (cultivars) do not differ (Scott-Knott test, $p<0.05) . \mathrm{CV}_{1}=$ coefficient of variation for systems; $\mathrm{CV}_{2}=$ coefficient of variation for cultivars.

dosage had a productivity near to that obtained for plants grown in unshaded conditions receiving $100 \%$ of the recommended fertilization. Jaramillo-Botero et al. (2006) authors associated the result to the fact that water and nutrients were absorbed for a longer time, since shading decreases evapotranspiration.

The most productive cultivars in the shaded system were Tupi, Obatã, and Catuaí, while no differences between cultivars were observed in coffee grown in the unshaded system (Table 3), considering average productivity of five and four years of production in both systems, respectively. Moura et al. (2005a) evaluated 31 coffee cultivars under the organic system in the municipalities of Araponga, Espera Feliz, and Tombos, in Minas Gerais, and the productivity obtained in bags processed per hectare (average of three municipalities) was: 43.33 (Catucaí amarelo 20/15), 30.30 (Oeiras MG 6851), 34.64 (Tupi IAC 1669-33), 20.75 (Icatu IAC 3282), 35.38
(Obatã IAC 1969-20), and 35.21 (Catuaí vermelho IAC 15). With exception to Catucaí, productivity obtained in both systems were compatible with the productivity achieved by Moura et al. (2005a) and higher than the national productivity average, which in the period from 2004 to 2009 ranged from 13.1 to 21.2 processed bags per hectare (ABIC, 2009).

Besides the presence of a tree component to enable modification of edaphic and non-edaphic characteristics in the growing environment, coffee is a species with good phenotypic plasticity, i.e., the capacity to express distinct phenotypes when exposed to different environments (Gotthard and Nylin, 1995). For this reason, coffee plants can undergo morphological transformations according to available radiation levels as a form of adaptation, as reported by different authors (Morais et al., 2003; 2004; Ricci et al., 2006; Gomes et al., 2008; Matos et al., 2009), and, therefore, express different productivity according to their growing environment. 
Table 3 - Productivity of coffee cultivars grown in subplots of unshaded or shaded conditions during the period 2003 to 2009*.

\begin{tabular}{|c|c|c|c|c|c|c|c|}
\hline \multirow{3}{*}{$\begin{array}{l}\text { Cultivar } \\
\text { Catucaí }\end{array}$} & \multicolumn{7}{|c|}{ Produtividade (60 kg bags per hectare) } \\
\hline & 2004 & 2005 & 2006 & 2007 & \multicolumn{2}{|c|}{2009} & Mean $* *$ \\
\hline & $16.4 \mathrm{Ab} \quad 14.6 \mathrm{Ab}$ & $10.2 \mathrm{Bb} 28.2 \mathrm{Aa}$ & $32.1 \mathrm{Ab} 39.8 \mathrm{Aa}$ & $14.8 \mathrm{Ab} 20.5 \mathrm{Aa}$ & --- & $38.1 \mathrm{~b}$ & $18.4 \mathrm{Ba} \quad 28.2 \mathrm{Ab}$ \\
\hline Oeiras & $30.1 \mathrm{Aa} \quad 17.4 \mathrm{Ab}$ & $26.4 \mathrm{Aa} 12.3 \mathrm{Bb}$ & $36.9 \mathrm{Aa} 51.4 \mathrm{Aa}$ & $23.5 \mathrm{Aa} 21.8 \mathrm{Aa}$ & --- & $31.1 \mathrm{c}$ & $29.2 \mathrm{Aa} \quad 26.8 \mathrm{Ab}$ \\
\hline Tupi & $28.8 \mathrm{Aa} \quad 27.9 \mathrm{Aa}$ & $24.7 \mathrm{Aa} 28.7 \mathrm{Aa}$ & $42.6 \mathrm{Aa} 44.1 \mathrm{Aa}$ & $24.4 \mathrm{Aa} 25.8 \mathrm{Aa}$ & --- & $49.7 \mathrm{~b}$ & $30.1 \mathrm{Aa} \quad 35.2 \mathrm{Aa}$ \\
\hline Icatu & $22.6 \mathrm{Aa} \quad 27.7 \mathrm{Aa}$ & $26.1 \mathrm{Aa} 32.5 \mathrm{Aa}$ & $35.9 \mathrm{Aa} 29.1 \mathrm{Ab}$ & $21.5 \mathrm{Aa} 23.0 \mathrm{Aa}$ & --- & $12.5 \mathrm{~d}$ & $26.5 \mathrm{Aa} \quad 25.0 \mathrm{Ab}$ \\
\hline Obatã & $27.9 \mathrm{Aa} \quad 31.3 \mathrm{Aa}$ & $15.8 \mathrm{Bb} 32.0 \mathrm{Aa}$ & $31.5 \mathrm{Ab} 36.6 \mathrm{Ab}$ & $18.9 \mathrm{Ba} 26.5 \mathrm{Aa}$ & --- & $41.3 \mathrm{~b}$ & $23.5 \mathrm{Ba} \quad 33.5 \mathrm{Aa}$ \\
\hline Catuaí & $17.5 \mathrm{Ab} \quad 16.6 \mathrm{Ab}$ & $21.7 \mathrm{Aa} 22.4 \mathrm{Aa}$ & $46.3 \mathrm{Aa} 36.5 \mathrm{Ab}$ & $21.5 \mathrm{Aa} 19.9 \mathrm{Aa}$ & --- & $62.0 \mathrm{a}$ & $26.8 \mathrm{Ba} \quad 31.5 \mathrm{Aa}$ \\
\hline Mean & $23.9 \mathrm{~A} \quad 22.6 \mathrm{~A}$ & $20.8 \mathrm{~A} \quad 26.0 \mathrm{~A}$ & $37.5 \mathrm{~A} \quad 39.6 \mathrm{~A}$ & $20.8 \mathrm{~A} \quad 22.9 \mathrm{~A}$ & --- & 39.1 & $25.8 \mathrm{~A} \quad 30.0 \mathrm{~A}$ \\
\hline $\mathrm{CV}_{1}(\%)$ & 51.2 & 31.6 & 64.2 & 10.5 & & 24.8 & 36.2 \\
\hline $\mathrm{CV}_{2}(\%)$ & 41.2 & 38.3 & 35.6 & 23.0 & & --- & 19.9 \\
\hline
\end{tabular}

Means followed by the same upper case letters in the row (management) and lower case letters in the column (cultivars) do not differ (Scott-Knott test, $p<0.05)$. $\mathrm{CV}_{1}=$ coefficient of variation for systems; $\mathrm{CV}_{2}=$ coefficient of variation for cultivars. *There was no production in 2008 due to stumping back (recepa) in 2007. **Mean of four harvests (sun) and five harvests (shaded).

\section{Conclusions}

Shading delayed fruit maturation. Late cultivars, such as Icatu and Obatã, maturated early in both cultivation systems, while medium and early maturation cultivars showed late maturation.

Shading increased the leaf area and the number of lower branches, decreased the number of productive nodes per branch, and increased the distance between the nodes and the number of leaves present on the branches.

The number of plants with 'branch blight' was higher in coffee plants grown in the unshaded system.

The productivity of the cultivars was equal, at 30.0 processed bags per hectare in the shaded system and 25.8 bags per hectare in the unshaded system.

The most productive cultivars in the shaded system were Tupi, Obatã, and Catuaí vermelho, while no differences between cultivars were obtained in the unshaded system.

\section{Acknowledgements}

To Brazilian Consortium for Coffee Research and Development for financial support to the project and for granting a Technical Support scholarship, and Foundation for Research of the State of Rio de Janeiro, also for financial support.

\section{References}

Associação Brasileira da Indústria do Café [ABIC]. 2009. Statistics: agricultural production. Available at: http://www.abic.com.br/ estat_pagricola.html. [Accessed Nov. 18, 2009]. (in Portuguese).

Altieri, M.A.; Silva, E.N.; Nicholls, C.I. 2003. The Role of Biodiversity in Pest Management. Holos, Ribeirão Preto, SP, Brazil. 226p. (in Portuguese).

Cannell, R. 1985. Physiology of the coffee crop. p. 108-134. In: Clifford, M.N.; Willson, K.C. (eds.). Coffee: botany, biochemistry and production of beans and beverage. Croom Helm, London, England.

Carvalho, C.H.C.; Rena, A.B.; Pereira, A.A.; Cordeiro, A.T. 1993. Relationship between crop load, N, P, K, Ca, Mg and starch content and the dieback of Catimor (Coffea arabica L.). Pesquisa Agropecuária Brasileira 28: 665-673. (in Portuguese, with abstract in English).
Carvalho, C.H.S. 2008. Coffee Cultivars: Origin, Characteristics and Recommendations. Embrapa Café, Brasília, DF, Brazil. (in Portuguese).

Da Matta, F.M. 2004. Ecophysiological constrains on the production of shaded and unshaded coffee: a review. Field Crops Research 86: 99-114.

Empresa Brasileira de Pesquisa Agropecuária [Embrapa]. National Research Center of Soil. 1997. Manual Methods of Soil Analysis. 2ed. Embrapa-CNPS, Rio de Janeiro, RJ, Brazil. 212p. (EMBRAPACNPS Documentos, 1). (in Portuguese).

Fahl, J.I.; Carelli, M.L.C.; Vega, J.; Magalhães, A.C. 1994. Nitrogen and irradiance levels affecting net photosynthesis and growth of young coffee plants (Coffea arabica L.). Journal of Horticultural Science 69: 161-169.

Freitas, R.B.; Oliviera, L.E.M.; Delú Filho, N.; Soares, A.M. 2003. Influence of different shading levels in physiological behavior of coffee cultivars (Coffea arabica L.). Ciência e Agrotecnologia 27: 804-810. (in Portuguese, with abstract in English).

Gliessman, S.R. 2000. Agroecology: ecological processes in sustainable agriculture. UFRGS, Porto Alegre, RS, Brazil. (in Portuguese).

Gomes, I.A.C.; Castro, E.M.; Soares, A.M.; Alves, J.D.; Alvarenga, M.I.N.; Alves, E.; Barbosa, J.P.R.A.D.; Fries, D.D. 2008. Morphophysiological alterations in leaves of Coffea arabica L. cv. 'Oeiras' shaded by Acacia mangium Willd. Ciência Rural 38: 109-115. (in Portuguese, with abstract in English).

Gotthard, K.; Nylin, S. 1995. Adaptive plasticity and plasticity as an adaptation: a selective review of plasticity in animal morphology and life history. Oikos 74: 3-17.

Guerreiro Filho, O.; Mendes, A.N.G.; Carvalho, G.R.; Silvarolla, M.B.; Botelho, C.E.; Fazuoli, L.C. 2008. Origin and botanical classification of coffee. p. 27-34. In: Carvalho, C.H.S., ed. Coffee cultivars: origin, characteristics and recommendations. Embrapa Café, Brasília, DF, Brazil. (in Portuguese).

Haggar, J.P.; Schibli, C.; Staver, C. 2001. How to handle shade trees in coffee plantations? Agroforestería en las Américas 8: 37-41. (in Spanish).

Jaramillo-Botero, C.; Santos, R.H.S.; Martinez, H.E.P.; Cecon, P.R.; Santos, C.R.; Perin, A. 2006. Reproductive development and yield of coffee plants under different levels of shade and fertilization. Revista Ceres 53: 343-349. (in Portuguese, with abstract in English).

Larramendi, L.R.; Aballes, O.P. 1995. Estimated area and leaf dry mass coffee grown in the sun and shade. Centro Agrícola 2: 15-20. (in Spanish).

Lemos, C.L.; Matsumoto, S.N.; Coelho, R.A.; Lima,J.M.; César, F.R.C.F.; Bonfim, J.A.; Guimarães, M.M.C.; Santos, M.A.F.; Araújo, G.S.; Souza, A.J.J. 2007. Evaluation of the vegetative development in coffee trees shading and the full sun. Revista Brasileira de Agroecologia 2: 1062-1065. (in Portuguese, with abstract in English). 
Magalhães, A.F.J. 2006. Mineral Nutrition and Fertilization of Irrigated Citrus. Embrapa Mandioca e Fruticultura Tropical, Cruz das Almas, BA, Brazil. (Circular Técnica, 79). (in Portuguese).

Matos, F.S.; Wolfgramm, R.; Gonçalves, F.V.; Paulo C.; Cavatte, P.C.; Ventrella, M.C.; Da-Matta, F.M. 2009. Phenotypic plasticity in response to light in the coffee tree. Environmental and Experimental Botany 67: 421-427.

Matsumoto, S.N. 2004. Shading coffee in Brazil. Editora UESB, Salvador, Bahia, Brazil. (in Portuguese).

Montoya, L.A.; Umaña, R. 1961. Effect of three light intensities and three levels of nitrogen (urea) on the intensity of dieback. Café 3: 1-8. (in Spanish).

Morais, H.; Marur, C.J.; Caramori, P.H.; Ribeiro, A.M.A.; Gomes, J.C. 2003. Physiological characteristics and growth of coffee plants grown under shade of pigeonpea and unshaded. Pesquisa Agropecuária Brasileira 38: 1131-1137. (in Portuguese, with abstract in English).

Morais, H.; Medri, M.E.; Marur, C.J.; Caramori, P.H.; Ribeiro, A.M.A.; Gomes, J.C. 2004. Modifications on leaf anatomy of Coffea arabica caused by shade of pigeonpea (Cajanus cajan). Brazilian Archives of Biology and Technology 47: 863-871.

Moura, W.M.; Lima, P.C.; Lisboa, J.M.M.; Pertel, J.; Ribeiro, P.M.; Pereira, A.A.; Rena, F.C.; Freitas, M.A.S. 2005a. Behavior of coffee cultivars in organic farming system in three municipalities of Minas Gerais. Available at: http://www.sbicafe.ufv.br/SBICafe/publicacao/ frpublicacao.asp. [Accessed Nov. 18, 2009]. (in Portuguese)
Moura, W.M.; Lima, P.C.; Souza, H.N.; Cardoso, I.M.; Mendonça, E.S.; Pertel, J. 2005b. Research into agroecosystems and organic coffee farming family in the Zona da Mata of Minas Gerais. Informe Agropecuário 26: 46-75. (in Portuguese).

Righi, C.A.; Lunz, A.M.P.; Bernardes, M.S.; Pereira, C.R.; Dourado Neto, D.; Favarin, J.L. 2008. Radiation availability in agroforestry system of coffee and rubber trees. p. 249-266. In: Shibu, J.; Gordon, A., eds. Toward agroforestry design: an ecological approach. Springer, Amsterdam, The Netherlands.

Ricci, M.S.F.; Fernandes, M.C.A.; Castro, C.M. 2003. Growing organic coffee: technical recommendations. 2002. Embrapa Informação Tecnológica, Brasília, DF, Brazil. (in Portuguese).

Ricci, M.S.F.; Costa, J.R.; Pinto, A.N.; Santos, V.L.S. 2006. Organic cultivation of coffee cultivars grown under full sun and under shading. Pesquisa Agropecuária Brasileira 41: 569-575. (in Portuguese, with abstract in English).

Ricci, M.S.F.; Costa, J.R.; Santos, V.L.S. 2007 Occurrence of branch blight in trees coffee grown under organic conditions in different plant spacings. Seropédica, RJ, Brazil. (Embrapa Agrobiologia. Documentos, 244). (in Portuguese).

Received March 04, 2010

Accepted December 12, 2010 